\title{
Testosterone and heterospecific aggression in the adult eastern bluebird (Sialia sialis) during the nestling period
}

\begin{abstract}
Conspecific competition is assumed to exert stronger selection than heterospecific competition on the aggressive behavior and its underlying physiology in birds. We tested the hypothesis that hormone-behavior interaction between testosterone and aggression may also be shaped by severe heterospecific competition among secondary cavity nesters. Adult Eastern Bluebirds $(n=34)$ were exposed to three challenge conditions that simulated territorial intrusions (STI) by heterospecific (House Sparrow) and conspecific using live and stuffed decoys with their respective playback vocalizations. Eastern Blue birds were responsive to simulated territorial intrusions (STIs) by Conspecific and heterospecific late in the nesting cycle. The aggressive response elicited from a heterospecific STI was muted compared to honspecific STI. Overall, highly aggressive individuals had slightly greater mean testosterone concentrations than individuals with low aggression scores. Baseline $\mathrm{T}$ and aggression were positively correlated for all STI conditions, but the relationship was strongest for the live heterospecific decoy. Furthermore, the live heterospecific decoy elicited a stronger aggressive response than the stuffed decoy suggesting that other cues produced by the living bird, in addition to the auditory and visual cues provided influenced individual responses to a challenger.
\end{abstract}

We conclude:

a. Conspecific competitors exert stronger selective pressure on the aggressive behavior than Heterospecific competitors.

b. Stuffed decoys may not accurately reflect the relationship between hormones and behavior in an individual.

Keywords: breeding season, interspecific aggression, intraspecific aggression, testosterone, simulated territorial intrusion
Volume I Issue I - 2016

Arboleda CV, Khan MZ

Wisconsin Veterinary Referral Center (WVRC), USA

Correspondence: Arboleda CV,Wisconsin Veterinary Referral Center (WVRC), 77I8W Green Tree Road, Milwaukee,WI 53223, 300 Seward Street, Ripon, Wisconsin, USA, Email arboleda_vanessa@hotmail.com

Received: January 3I, 2015 | Published: January 4, 2016

\section{Introduction}

During the breeding season, birds establish territories and aggressively defend them against intruders. In general, conspecific intruders elicit greater behavioral responses than heterospecific because heterospecifics are not usually competing for the same resources. Interference competition, through aggressive interactions between species, has the potential to affect community structure. ${ }^{1}$ In male birds the steroid hormone testosterone, mediates territorial aggression. ${ }^{2}$ Testosterone and aggression has been studied relative to seasonal cycles ${ }^{3}$ and population density Beletsky et al. ${ }^{4}$ Species differences in testosterone and aggression may influence their dispersal ability ${ }^{5}$ and geographic distributions. ${ }^{6}$ Aggression towards conspecifics and heterospecifics may be mediated by the same physiological pathways and we test this hypothesis here.

Nest box trails, a popular management tool, provide an opportunity to examine heterospecific competition because of relatively small distances between cavities and placement of boxes in suburban environments which harbor nest box competitors like House Sparrows (Passer domesticus) and European Starlings (Sturnus vulgaris). Among secondary cavity nesting birds, interspecific aggression is more common because of limited cavity availability. For example, Collared Flycatchers (Fidecula Albicollis) are most aggressive toward
Great Tits (Parus major), another cavity nester, and least aggressive toward Dunnocks (Prunella modularis), an open-cup nester. ${ }^{7}$

The challenge hypothesis states that circulating testosterone rises above baseline concentrations in response to competition for mates and territory. A rise in testosterone in response to social challenges strengthens subsequent sexual displays and prolongs the duration of aggressive behaviors. ${ }^{8,9,10}$ Tests of the challenge hypothesis focus on behavioral and physiological responses to conspecific intrusion ${ }^{11,12}$ because conspecific competition is assumed to be stronger selective factor than heterospecific competition. This assumption is under scrutiny and should be tested. ${ }^{1}$ We tested the hypothesis that testosterone and aggression levels may correlate with heterospecific competition as well.

We examined the relationship between baseline circulating testosterone and the expression of aggressive behavior of adult eastern bluebirds to different competitor challenges during the late nestling period. Eastern Bluebirds, Sialia sialis, are obligate secondary cavity nesters that compete with other cavity nesting species. We addressed two questions in this study. First, are Eastern Bluebirds responsive to simulated territorial intrusions (STIs) by conspecifics and heterospecifics late in the nesting cycle? Even after establishment of territories they remain at risk of intrusions by House Sparrows ${ }^{13,10}$ 
and male bluebirds. ${ }^{14,15}$ Both types of intrusion may compromise an individual's reproductive success, conspecifics via cuckoldry ${ }^{14}$ and sparrows by direct mortality to nestlings. ${ }^{13}$ Furthermore, we expected males to react more aggressively to conspecific challenges because in a reproductive perspective, males are the only individuals for whom a conspecific intrusion is a greater disadvantage.

Second we asked if baseline testosterone concentrations and aggressive behavior covary within individuals. We predict individuals with high baseline testosterone concentrations will exhibit more aggression than males with lower testosterone concentrations. We used baseline testosterone because it likely indicates the long-term social environment of the individual. Males exposed to more territorial intrusions exhibit higher baseline $\mathrm{T}$ than males in less competitive environments. ${ }^{16}$

\section{Methods}

Monitoring: The study area consisted of nest boxes on the grounds of Ripon College, backyards and municipal parks of Ripon, Wisconsin $\left(43^{\circ} 50^{\prime} 40^{\prime \prime} \mathrm{N} 88^{\circ} 50^{\prime} 20^{\prime \prime} \mathrm{W}\right)$. Nest boxes were monitored weekly from April-August in 2009 to determine occupancy by bluebirds, nesting phase and nest success. Once a bluebird nest was identified, boxes were checked twice a week during the incubation period (12-14 days). Daily monitoring of bluebird nests started two days before hatching, and continued until day 13 to avoid premature fledging. ${ }^{17}$

Capture and blood sampling: The relationship between aggression and circulating testosterone concentration in male and female eastern bluebirds was examined by correlating behavioral responses to simulated territorial intrusions (STIs) to hormone concentrations measured in blood plasma. Adult birds $(N=34)$ were captured with remote control nest- box traps when nestlings were ten days old. We used a mist net and a conspecific decoy with playback vocalizations as a method of capture when the remote trap was not effective. Because capture may affect hormone concentrations in blood ${ }^{8}$ the method of capture and the time between capture and blood collection were included in subsequent statistical analyses. Blood samples were collected from adult birds within $6.53 \pm 0.34$ min $(m e a n \pm S D)$ after capture, well within the ten minute window before the stress of capture causes testosterone to decline. ${ }^{18}$ For blood collection, we punctured the brachial vein with a 26 gauge needle and drew approximately $240 \mu 1$ of blood using heparinized microhematocrit capillary tubes. ${ }^{8}$ Blood samples were placed into a cooler in the field, and transported

Table I Criteria for scoring aggressive behavior of eastern bluebirds based on

\begin{tabular}{lllll}
\hline \multirow{2}{*}{ Score } & \multicolumn{1}{l}{ Behavior } & Number of attacks & Qualitative description \\
\cline { 2 - 4 } & Number of times flying or hovering & 0 & No aggressive behaviors \\
\hline I & 0 & 0 & Minimal response, moderately aggressive behaviors \\
3 & $1-5$ & 0 & Moderate response, moderately aggressive behaviors \\
4 & $>5$ & -- & $1-5$ & Moderate response, highly aggressive behaviors \\
5 & -- & $6-9$ & High response, highly aggressive behaviors \\
6 & -- & $>9$ & Very high response, many highly aggressive behaviors
\end{tabular}

\section{Hormone analysis:}

Blood samples were centrifuged in hematocrit capillary tubes at $3460 \mathrm{xG}$ for five minutes in order to separate red blood cells from to the lab within four hours to be stored at $-80^{\circ} \mathrm{C}$. During capture we measured each bird's mass $(\mathrm{g})$, right tarsus length $(\mathrm{mm})$, and right wing chord length $(\mathrm{mm})$ to reflect an individual's quality. Unbanded individuals were banded with a unique color combination of bands (Master banding permit \#23473) and a USFWS numbered aluminum band.

Behavioral observation: Most observations started a day after capture of the box (unless observations occurred during capture), when nestlings were 11 days old, and were completed on day 13 (three days after capture) so that simulated intrusions did not influence the measurements of circulating testosterone.

We modified methods from Duckworth ${ }^{10}$ \& Wingfield et al. ${ }^{19}$ We simulated a conspecific intrusion by placing a prepared skin of a male Eastern Bluebird (conspecific decoy=CD) on top of the nest box while playing a recording of the bluebird song. Because bluebirds have aggressive encounters with House Sparrows even after establishment of territory ${ }^{13}$ we simulated a heterospecific intrusion by presenting a House Sparrow while playing a recording of its song. Heterospecific intrusions were modeled in two ways, with a prepared skin (heterospecific decoy=HD) or with a living bird in a cage (heterospecific caged=HC). Each nest box was exposed to all three conditions $(\mathrm{CD}, \mathrm{HD}$, and $\mathrm{HC})$ in a randomly assigned order, with each observation lasting approximately five minutes $(4.40 \pm 1.66 \mathrm{~min})$.

Some observations were terminated earlier because of an unexpected equipment failure, or because the decoy was damaged by attacks. We recorded behaviors using a tape recorder, and a Flip Video mini-HD camera placed approximately $15 \mathrm{~m}$ from the box on a tripod. To quantify aggression we analyzed video playbacks and measured the latency of first attack on the decoys in addition to the number of attacks, hovering, and fly-overs. All behaviors were analyzed as frequency per minute to control for the different observation times during each STI. Vocalizations were also recorded, but genders were combined because we could not distinguish the vocalizations of males from females. We did not analyze vocalizations during trials with conspecific decoys because we could not distinguish the calls made on the recording from the calls made by the defending birds.

Aggressive behavior was scored on a scale of 1-6 as described by Duckworth ${ }^{10}$ one indicating a slight response and six a strong response (Table 1). We standardized our behavioral data by dividing the frequency by the time observed and multiplying by two to be consistent with Duckworth's criteria of 2 minute observations. plasma, and the plasma was transferred into $0.5 \mathrm{ml}$ microcentrifuge tubes using a Hamilton syringe. Final samples were stored at $-80^{\circ} \mathrm{C}$ until laboratory analysis. 
We used methods described by O'Fegan ${ }^{20}$ to validate the Salivary Testosterone Enzyme Immunoassay (EIA) kit (Salimetrics). The EIA kit is capable of measuring testosterone in small-volume avian plasma, ${ }^{21}$ and is sensitive enough to detect biological changes in the gonadal activities of small birds. ${ }^{22}$ The slopes of serial dilutions were parallel to the standard curve for male plasma $(t=-0.25, \mathrm{p}=0.81)$ and female plasma $(t=-0.11, \mathrm{p}=0.91)$ indicating that bluebird plasma does not interfere with the ability of the anti-testosterone antibody of the Salimetrics kit to bind to testosterone in avian blood samples. ${ }^{23}$ Intraassay variation for high controls was $1.63 \% \pm 2.00$ and $12.69 \% \pm 6.09$ for low controls. Inter-assay variation was $7.37 \%$ and $7.60 \%$ for high and low controls respectively. Male samples were diluted to 1:4 plasma/ assay diluents and female plasma was not diluted due to the expected low concentrations of testosterone. Plasma from individuals with very low testosterone concentrations was spiked using $24 \mathrm{pg} / \mathrm{ml}$ standard and unknown concentrations were then back calculated.

Statistical analysis: Statistical analyses were performed using SPSS 19.0 (IBM, Chicago, IL USA) and. ${ }^{24}$ For this study we performed all behavioral analysis using parametric statistics and corrected for small sample sizes using the Bonferroni method. A t-test was carried out to compare accuracy of measure by voice recording and a video camera. There was no statistical difference between the data taken by either medium $\left(t_{50}=0.40 ; P=0.69\right)$, therefore I assumed that the same conclusions would be reached by analyzing either one. I chose to analyze fly-over data collected by voice recording because the field of view of the video camera was too narrow. Attacks, vocalizations and hovers were analyzed using video recordings. ${ }^{25}$

The effect of conspecific or heterospecific intruders on aggressive behavior was examined using a Multivariate Analysis of Variance (MANOVA), where rates of behaviors were compared among the treatment conditions and between males and females. Testosterone concentrations in males and females were compared using a t-test. The relationships between testosterone and aggression scores were analyzed with linear regression. All results are presented as mean \pm standard deviation unless noted otherwise.

\section{Results}

\section{Simulated territorial intrusions}

The simulated territorial intrusions elicited responses from the bluebirds $(1.08 \pm 0.31 \mathrm{~min}, \quad N=23)$. Males $(0.72 \pm 1.14 \mathrm{~min}, \quad N=18)$ responded more quickly than females $(1.45 \pm 2.12 \mathrm{~min}, N=7)$. Both adults reacted differently to the simulated intrusions of heterospecific and conspecific competitors $\left(F_{2}=10.61, P<0.001\right)$. The amplitude of their response was greater if the decoy was a living bird compared to a stuffed skin. Both sexes attacked, hovered and flew-over the living House Sparrow more often than the stuffed decoy (Figure 1). The total number of vocalizations produced by both males and females was significantly greater toward the living House Sparrow (Figure 2, one-way ANOVA, $F=0.88, P<0.006$ ). All other comparisons were restricted to simulated intrusions with stuffed decoys because we were more interested in the comparing aggressive responses of bluebirds toward conspecifics and heterospecific intruders.

\section{Aggression}

Males tended to be more aggressive than females toward any decoy when attacking (Figure $1 ; F=16.29, P=0.00$ ), or hovering $\left(F_{l}=2.85, P=0.10\right)$ but not when flying over the decoy $\left(F_{l}=1.21, P=\right.$ 0.730 ). Overall, the resident pair acted more aggressively toward the conspecific decoy than the heterospecific decoy during attacks
$\left(F_{l}=4.87, P=0.03\right)$ and hovers $\left(F_{l}=9.81, P=0.003\right)$ but not during flyovers $\left(F_{I}=1.26, P=0.27\right)$.
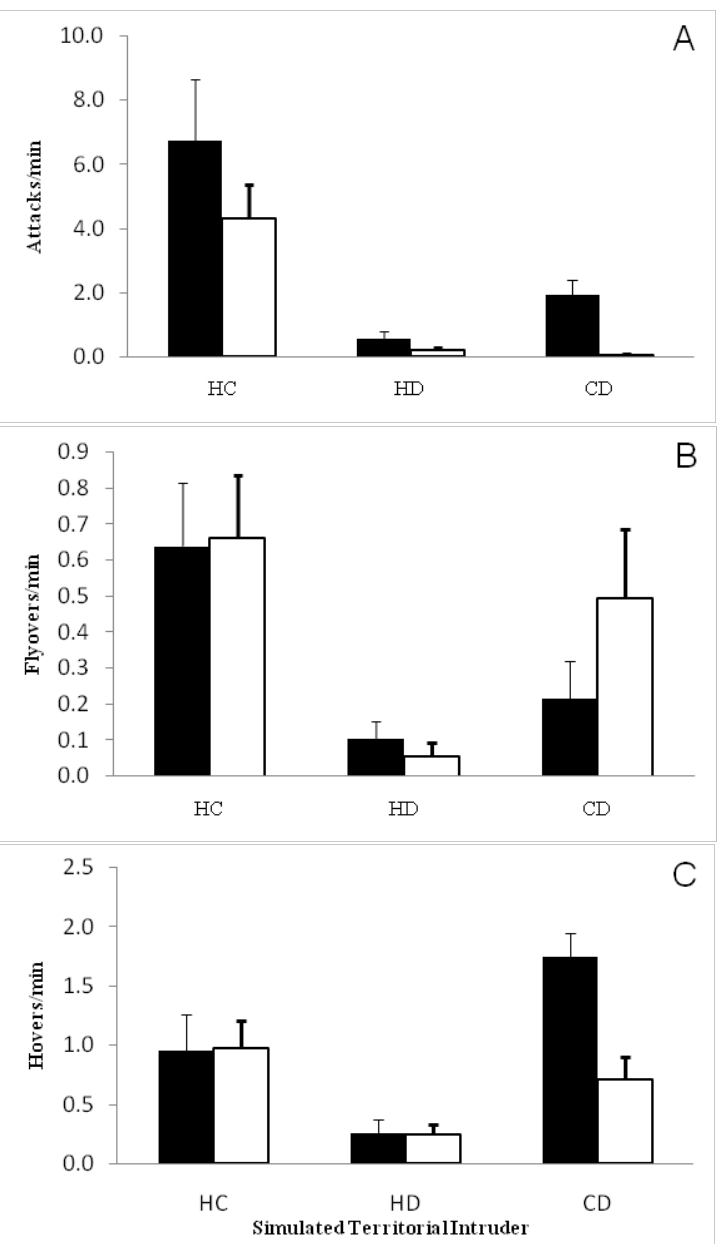

Figure I The mean aggressive responses $( \pm \mathrm{SE})$ measured as attacks $(\mathrm{A})$, flyovers (B), and hovers (C) were similar for male (black bars) and female (white bars) Eastern Bluebirds. Bluebirds reacted to simulated territorial intrusions by a live caged heterospecific $(\mathrm{HC})$ more than a heterospecific stuffed decoy $(\mathrm{HD})$ or conspecific decoy (CD).

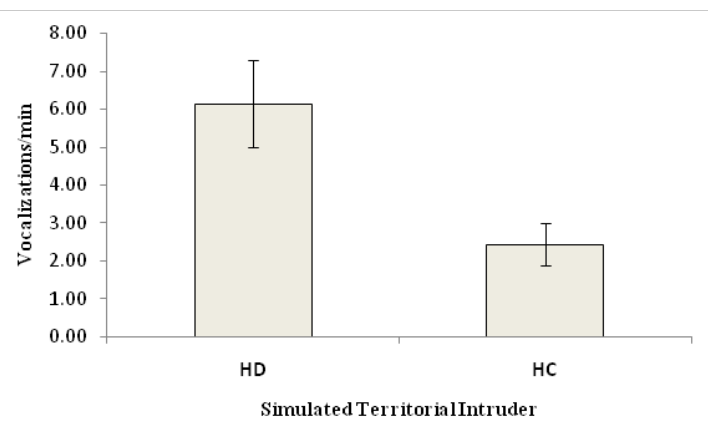

Figure 2 Eastern Bluebirds (male and female data pooled) vocalized (mean \pm SE) more frequently during a simulated territorial intrusion of a heterospecific stuffed decoy $(H D, N=13)$ compared to a live caged intruder $(H C, N=14)$.

\section{Testosterone and aggression}

Males exhibited marginally higher testosterone concentrations than females (Figure $3, t=1.88, p=0.05$ ). On average, individuals that exhibited high aggression did not differ in circulating testosterone than individuals that exhibited low aggression among males (Figure 
4, one-way ANOVA, $\left.F_{l}=0.16, P=0.71\right)$ or females $\left(F_{I}=2.34, P=0.16\right)$. Females paired to males had weakly correlated aggression scores (Figure $5 \mathrm{~A}, F_{l}=4.03, P=0.07$ ) and testosterone concentrations (Figure $5 \mathrm{~B})$.

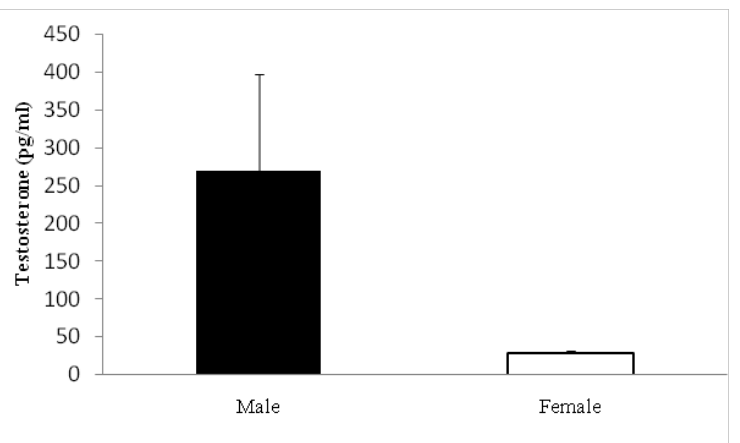

Figure 3 Male Eastern Bluebirds $(N=8)$ exhibited higher mean $( \pm S E)$ baseline plasma testosterone concentrations than females $(N=10)$ when the pair was tending 10 day old nestlings.

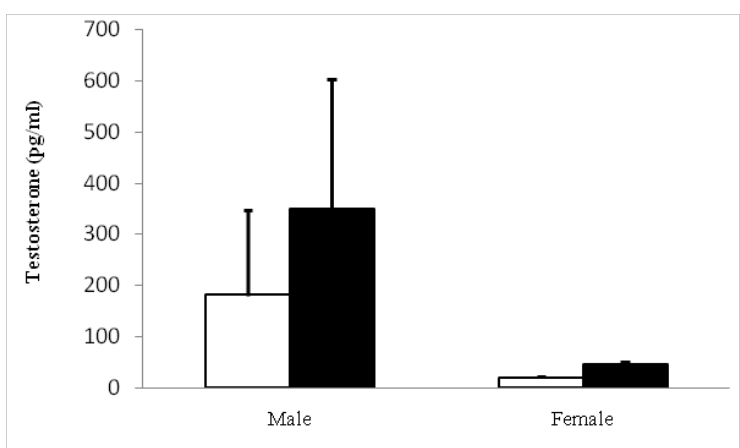

Figure 4 Male $(N=6)$ and female $(N=10)$ Eastern Bluebirds that exhibited high aggression (black bars) scores during simulated territorial intrusions have higher mean $( \pm \mathrm{SE})$ baseline plasma testosterone concentrations than birds with low aggression scores (white bars)

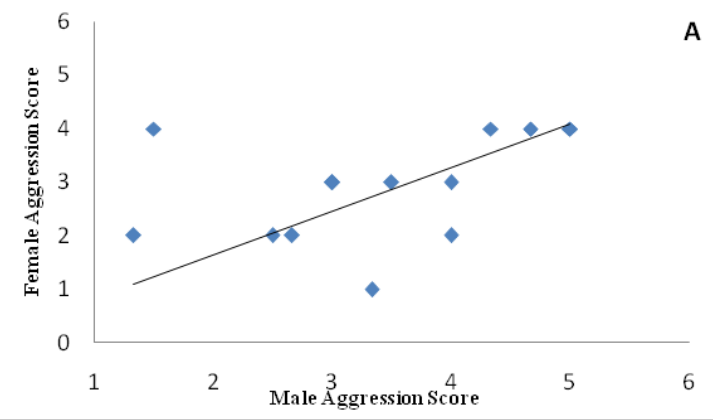

Figure 5(A) Males and female eastern bluebirds in a mated pair exhibited positively correlated aggression scores.

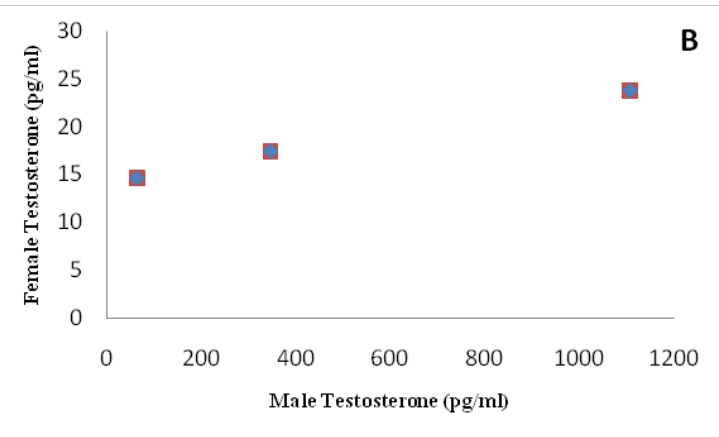

Figure 5(B) Testosterone concentrations.

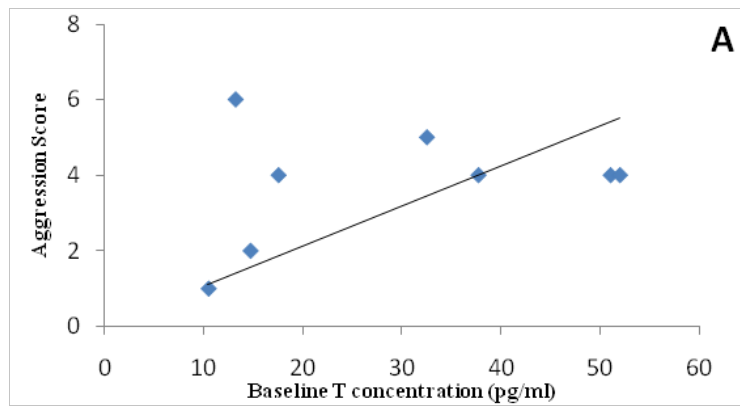

Figure 6(A) Baseline plasma testosterone concentrations of male Eastern Bluebirds were positively correlated with aggression scores in each simulated territorial intrusions by a conspecific stuffed decoy.

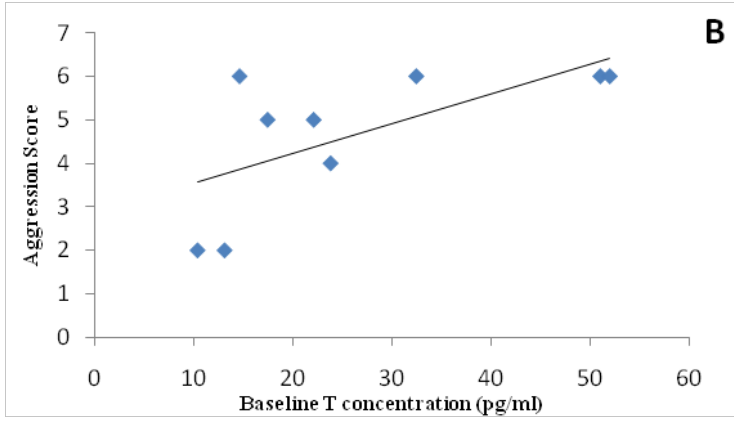

Figure 6(B) Heterospecific stuffed decoy.

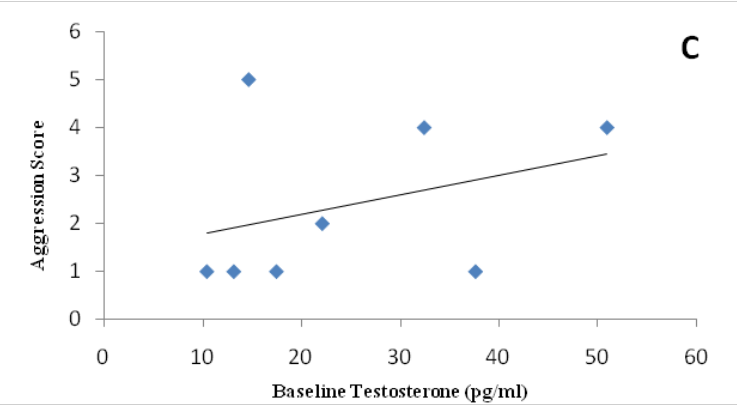

Figure 6(C) Live caged heterospecific.

We explored the relationships between aggression scores and baseline testosterone for male bluebirds in each of the three STIs. Every STI exhibited a positive correlation between baseline testosterone concentration and individual aggression scores (Figure 6A-6C) but the relationship was insignificant for responses to the conspecific decoy $\left(F_{l}=0.57, P=0.48\right)$, and the heterospecific decoy $\left(F_{l}=0.80\right.$, $P=0.40$ ). Interestingly, the positive correlation between testosterone and aggression was marginally significant for the male bluebird's response to the heterospecific caged decoy $\left(F_{1}=5.03, P=0.06\right)$.

\section{Discussion}

Are bluebirds responsive to territorial intrusion late in the nesting cycle?

Eastern bluebirds compete fiercely for limited cavity space against other cavity nesters even after establishment of territories. Based on the challenge hypothesis we predicted that Eastern Bluebird aggression would be maintained late in the nesting cycle because of their vulnerability to intrusions by both conspecifics and heterospecifics. In this study, STIs by conspecific and heterospecifics elicited aggressive responses by males and females, indicating that eastern bluebirds perceive conspecific and heterospecific intruders as a threat. 
Among males, the level of response toward the heterospecific decoy was lower than toward the conspecific decoy. Perhaps the risk of nest failure from House Sparrow cavity usurpationis less than the risk of losing paternity to a conspecific male. Eastern Bluebirds in the Midwestern US attempt second broods, ${ }^{26}$ so males may still need to guard against sexual competitors late in the nesting cycle of first broods. To determine if Eastern Bluebirds are responding to risk probabilities, we suggest examining aggressive responses under conditions of different conspecific and heterospecific density and intruders with different risks. For example, one should compare the aggressive responses of Eastern Bluebirds to Black-capped Chickadees who pose little risk of nest box usurpation to that of House Wrens (Troglodytes troglodytes) which often destroy Eastern Bluebird nests. Lehtonen demonstrated that cichlid fish modulated their aggressive responses depending on the risk (breeding or nonbreeding colors) posed by a heterospecific intruder.

We measured Eastern Bluebirds aggression using three different metrics, direct attacks, hovering, and flyovers. Compared to males, females were less likely to attack and more likely to flyover conspecific decoy. These different responses could be explained by the different reproductive strategies of each sex. Eastern Bluebirds are known to double brood and occasionally change mates during a given breeding season. ${ }^{27}$ Male Eastern Bluebirds mate-guard and drive away sexual competitors ${ }^{15}$ who explain the attack behavior observed in this study. Female flyover behavior may be interpreted as her assessment of a potential new sexual partner.

Do baseline $\mathrm{T}$ and aggressive behavior covary among individuals?

Males exhibited marginally higher circulating testosterone than females which is not surprising given that blood sampling occurred late in the nesting cycle, suggesting that testosterone levels in males are lower than at the beginning of the nesting period. In socially monogamous double-brooded species, circulating levels of testosterone reach a peak during the egg-laying phase, and remain at lower levels during the parental phase and into the second sexual phase. ${ }^{28}$ Male Eastern Bluebirds provide parental care during the nestling and fledgling phases..$^{29}$ In many species parental behavior is depressed if testosterone is experimentally elevated revealing a trade-off between current and future reproductive success. ${ }^{30}$ That we observed similar male and female testosterone concentrations in this study likely represents this trade-off in Eastern Bluebirds.

Highly aggressive individuals had marginally greater mean baseline testosterone concentrations than individuals with low aggression scores, but the differences were not statistically significant. We assumed that individual differences in baseline testosterone could be attributed to differences in social context and not seasonal variation because each bird was sampled at a standardized time in the nestling cycle, when nestlings were 10 days old. However, circulating levels of androgens may only correlate with aggression during periods of instability. We assumed instability in this study because nest losses to House Sparrow usurpation occur throughout the breeding season (pers. obs) but this assumption was not tested. Future studies should test this assumption by quantifying heterospecific density in the study area. We also assumed that social interactions had an additive effect on baseline testosterone such that males with higher baseline $\mathrm{T}$ were exposed to greater social instability. Recent work on Great Tits and Stonechats indicate that this assumption may be naïve. ${ }^{31}$ Future studies should measure both seasonal testosterone patterns and the changes in testosterone in response to STIs.
Other mechanisms may contribute to aggressive behaviors during the parental phase as well, when testosterone needs to be maintained at lower levels. Testosterone remains at higher than basal levels throughout the breeding season for many species, ${ }^{8}$ but it seems to contribute little to aggression observed during the non-breeding season..$^{32}$ The variability of aggressive responses among individuals and the lack of apparent relationship with their respective testosterone levels could be attributed to individual sensitivity to circulating testosterone, ${ }^{30}$ or other hormones such as estrogen may mediate aggression when testosterone is low. ${ }^{33}$

Our data show a weak correlation between aggression scores and testosterone concentrations of breeding pairs. Recent studies have demonstrated that the testosterone cycle in females co-varies with males such that and peak levels of testosterone are present during pre-laying and remain high during egg-laying. ${ }^{34,35,36}$ Our correlations between male and female aggression scores suggest several new hypotheses. Perhaps aggressive males attract aggressive females through assortative mating; however other traits are likely to be more important for mate choice decisions. ${ }^{37} \mathrm{~A}$ more likely explanation is the shared social environment of the breeding pair. In many species, testosterone in females is also strongly correlated with territorial aggression. . $^{38,39,40}$

\section{Do aggressive responses depend on STI?}

A significantly greater aggressive response was directed towards the caged living house sparrow than toward the prepared skin decoy; both adults spent more time attacking the live challenger. In addition, the prepared skin decoy elicited significantly more frequent vocalizations from the Eastern Bluebirds than the live decoy. A living bird likely provides cues beyond the visual and auditory cues provided in this study with the prepared skin decoy and song recordings allowing the adults to accurately identify the intruder. We only detected a correlation between testosterone and aggression in the live caged bird, providing further evidence that that we weren't accurately measuring aggressive behavior when we used a prepared skin decoy. These concerns have been raised by others who noted that the methods used during STIs, e.g. living versus stuffed decoys, length of stimulation; behavior of living decoy may affect experimental outcomes and confound meaningful interpretation. ${ }^{31}$

\section{Conclusion}

In conclusion, we have shown that a conspecific competitor stimulated aggression more strongly than a heterospecific competitor which is consistent with the assumption that conspecific competition is more important for the evolution of aggressive behavior than heterospecific competition. The influence of heterospecific competition cannot be completely discounted because testosterone and aggression positively correlated for all STIs albeit weakly. Our study raises concern about using stuffed decoys to simulate territorial intrusions because the greatest responses were stimulated by the living heterospecific decoy. We propose that the influence of heterospecific competitors should be studied in more detail using more effective STI methods.

\section{Acknowledgements}

This research was supported by the U.S. Department of Education through the McNair Scholars Program. Melissa Meierhofer provided invaluable assistance in the field. 


\section{Conflict of interest}

The author declares no conflict of interest.

\section{References}

1. Peiman KS, Robinson BW. Ecology and evolution of resource-related heterospecific aggression. Q Rev Biol. 2010;85(2):133-158.

2. Wingfield JC. Control of territorial aggression in a changing environment. Psycho-neuroendocrinology. 1994;19(5-7):709-721.

3. Johnsen TS. Behavioral correlates of testosterone and seasonal changes of steroids in red-winged blackbirds. Anim Behav. 1998;55(4):957-965.

4. Beletsky LD, Orians GH, Wingfield JC. Year-to-year patterns of circulating levels of testosterone and corticosterone in relation to breeding density, experience, and reproductive success of the polygynous red-winged blackbird. Horm Behav. 1992;26(3):420-432.

5. Duckworth RA, Badyaev AV. Coupling of dispersal and aggression facilitates the rapid eange expansion of a passerine bird. Proceeding National Academy of Sciences. 2007;104(38):15017-15022.

6. Owen-Ashley N, Butler L. Androgens, interspecific competition and species replacement in hybridizing warblers. Proc Biol Sci. 2004;271(Suppl 6):S498-S500.

7. Krist M. Importance of competition for food and nest-sites in aggressive behavior of Collared Flycatcher (Fidecula albicollis). Bird Study. 2004;51:41-47.

8. Wingfield JC, Moore MC. Hormonal, social and environmental factors in the reproductive biology of free-living male birds. In Psychology and Reproductive Behavior: An Evolutionary Perspective. US: PrenticeHall; 1987. p. 149-175.

9. Duyse EV, Pinkton R, Eens M. Does testosterone affect trade-off between investment in sexual/territorial behavior and parental care in male great tits? Behavior. 2000;137:1503-1515.

10. Duckworth RA. Behavioral correlates across breeding contexts provide a mechanism for a cost of aggression. Behavioral Ecology. 2006;17(6):1011-1019.

11. Wingfield JC, Lewis DM. Hormonal and behavioral responses to simulated territorial intrusion in the cooperatively breeding whitebrowed sparrow weaver, Plocepasser mahali. Animal Behavior. 1993;45(1):1-11.

12. Moore I, Wada H, Perfito N, et al. Territoriality and testosterone in an equatorial population of rufous-collared sparrows, Zonotrichia capensis. Animal Behavior. 2004;67(3):411-420.

13. Gowaty PA. House Sparrows kill eastern bluebirds. Journal of Field Ornithology. 1984;55(3):378-380.

14. Gowaty PA, Bridges WC. Nestbox availability affects extra-pai fertilization \& conspecific nest parasitism in eastern bluebird, Sialia sialis. Anim Behav. 1991;41(4):661-675.

15. Meek SB, Robertson RJ. Interspecific competition for nestboxes affects mate guarding in eastern bluebirds (Sialia sialis). Anim Behav. 1994;47(2):295-302.

16. Silverin B. Territorial behavior and hormones of pied flycatchers in optimal and suboptimal habitats. Anim Behav. 1998;56(4):811-818.

17. Moore I, Wada H, Perfito N, et al. Territoriality and testosterone in an equatorial population of rufous-collared sparrows, Zonotrichia capensis Animal Behavior. 2004;67(3):411-420.

18. Wingfield JC, Farner DS. Avian Endocrinology: Field Investigations and methods. The Condor. 1976;78:570-573.
19. Wingfield JC, Ball GF, Dufty AM, et al. Testosterone and aggression in birds. American Scientist. 1987;75:602-608.

20. O'Fegan PO. Validation. In Immunoassays. In: Gosling JP, editor. New York: Oxford University Press; 2000. p. 211-238.

21. Washburn B, Millspaugh JJ, Morris DL, et al. Using a commercially available enzyme immunoassay to quantify testosterone in avian plasma. The Condor. 2007;109:181-186.

22. Meier AH, Martin DD, Mac Gregor R. Temporal synergism of corticosterone and prolactin controlling gonadal growth in sparrows. Sci. 1971;173(4003):1240-1242.

23. Wingfield, JC. Short-term changes in plasma levels of hormones during establishment and defense of a breeding territory in male song sparrows, Melopzia melodia. Horm Behav. 1985;19(2):174-187.

24. Microsoft $^{\circledR}$ Excel. [computer program] Microsoft Corporation. Redmond, WA; 2007.

25. $\mathrm{IBM}^{\circledR}$ SPSS $^{\circledR}$ Statistics Version 19.0 [computer program]. NY: IBM Armonk.

26. Pinkowski BC. Breeding adaptations in the Eastern Bluebird. Condor. 1977;79:289-302.

27. Gowaty PA, Plissner JH. Breeding dispersal of eastern bluebirds depends on nesting success but not on removal of old nests:An experimental study. Journal of Field Ornithology. 1997;68(3):323-330.

28. Gaunt AS, Oring LW, Able KP, et al. Guidelines to the use of wild birds in research. In: Gaunt AS, Oring LW, editors. The Ornithological Council. USA; 1987. p. 29-34.

29. Gowaty PA, Plissner JH. Eastern Bluebird (Sialia sialis). In: Poole A, editor. The Birds of North America Online Ithaca: Cornell Lab of Ornithology: the Birds of North America Online. Canada; 1998.

30. Hau M. Regulation of male traits by testosterone: implication for the evolution of vertebrate life-histories. Bioessays. 2007;29(3):133-144.

31. Goymann W, Landys M, Wingfield J. Distinguishing seasonal androgen responses from male-male androgen responsiveness-Revisting the Challenge Hypothesis. Hormones and Behavior. 2007;51(4):463-476.

32. Wingfield JC, Hahn TP. Testosterone and territorial behavior in sedentary and migratory sparrows. Animal Behavior. 1994;47(1):77-89.

33. Soma KK, Tramontin AD, Wingfield JC. Oestrogen regulates male aggression $\mathrm{n}$ the non-breeding season. Proc Biol Sci. 2000;267(1448):1089-1096

34. Jawor JM, McGlothin JW, Castos JM, et al. Testosterone response to $\mathrm{GnRH}$ in a female songbird varies with stage of reproduction: implications for adult behavior and maternal effects. Functional Ecology. 2007;21(4):767-775.

35. Ketterson ED, Nolan V, Sandell M. Testosterone in females. Mediator of adaptive traits, constraint on sexual dimorphism, or both? American Naturalist. 2005;166:S85-S98.

36. Ketterson ED, Nolan V, Wolf L, et al. Testosterone and avian life histories: Effects of experimentally elevated testosterone on behavior and correlates of fitness in the dark-eyed junco (Junco hyemalis). American Naturalist. 1992;140:980-999.

37. Siefferman L, Hill G. Blue structural coloration of male eastern bluebirds, Sialia sialis predicts incubation provisioning to females. Journal of Avian Biology. 2005;36(6):488-793.

38. Wingfield JC. Hormone--behavior interactions and mating systems in males and female birds. In: Short RV, Balaban E, editors. The differences between the sexes. UK: Cambridge University Press; 1994. p. 303-330. 
39. Elekonich MM, Wingfield JC. Seasonality and hormonal control of territorial aggression in female song sparrows (Passeriformes: Emberizidae: Melospiza melodia. Ethology University of Washington. 2000;106(6):493-510.
40. McGlothlin JW, Neudorf DLH, Castro JM, et al. Elevated testosterone reduces choosiness in female dark-eyed juncos (Juncoshyemalis): evidence for a strong constraint on sexual selection? Proceedings: Biological Sciences. 2004;271(1546):1377-1384. 